\title{
Resistência ao Cisalhamento Interlaminar de Compósitos com Resina Epóxi com Diferentes Arranjos das Fibras na Presença de Vazios
}

\author{
Michelle L. Costa, Sérgio F. M. de Almeida \\ Instituto Tecnológico de Aeronáutica, CTA
}

\author{
Mirabel C. Rezende \\ Divisão de Materiais, Instituto de Aeronáutica e Espaço, CTA
}

\begin{abstract}
Resumo: A presença de vazios em compósitos estruturais pode ter efeitos significativos. Em geral, os vazios diminuem a resistência estática e a vida em fadiga de laminados. Essa influência é bastante pronunciada na resistência ao cisalhamento interlaminar, compressão, entre outras, onde as propriedades mecânicas da matriz exercem maior influência sobre o comportamento do compósito. O presente artigo descreve o estudo do efeito da porosidade na resistência ao cisalhamento interlaminar de sistemas de compósitos de tecido e tape (fitas unidirecionais) de carbono aglutinados com matriz epóxi. Os laminados foram produzidos de maneira semelhante, bem como o processo de introdução de vazios (na faixa de 0 a $12 \%$ de porosidade). Os compósitos foram avaliados por análises microscópicas e inspeção ultra-sônica e os valores de atenuação medidos foram convertidos em coeficientes de absorção para permitir uma normalização dos dados. O critério de fratura de Mar-Lin apresentou bom ajuste, mostrando-se adequado para o estudo de porosidade em compósitos. Por meio desse critério foi determinado que somente os laminados com porosidade acima de $0,9 \%$ para tecido de carbono/epóxi e acima de $0,75 \%$ para laminados de tape de carbono/epóxi é que apresentam redução de suas propriedades mecânicas
\end{abstract}

Palavras-chave: Vazios, compósitos, resistência ao cisalhamento interlaminar, critério de falha.

\section{Interlaminar Shear Strength of Composites with Epoxy Resin with Different Arrangement of Fibers in the Presence of Voids}

\begin{abstract}
The presence of voids has deleterious effects on the structural performance of composites. In general, voids decrease the static strength and lifetime under fatigue. The influence is more pronounced in the interlaminar shear strength (ILSS), compressive strength, and others that are associated with matrix- dominated mechanical properties. This work reports the effect of porosity on the interlaminar shear strength (ILSS) of epoxy-impregnated carbon fabric and tape composites. Several laminates with different void content (porosity range of $0-12 \%$ ) were prepared in a similar way. The composites were characterized by microscopy and ultrasonic inspection with the attenuation values being converted in absorption coefficients and correlated with ILSS results. The Mar-Lin fracture criterion provided a good fit to the experimental data and was deemed adequate to predict the strength of porous composites. It was observed that carbon fabric laminate with porosity level higher than $0.9 \%$ and carbon tape laminates with porosity above $0.75 \%$ led to the reduction of the mechanical strength.
\end{abstract}

Keywords: Voids, composites, interlaminar shear strength, fracture criterion.

Autor para correspondência: Mirabel C. Rezende, Divisão de Materiais, Instituto de Aeronáutica e Espaço, CTA, CEP: 12288-904, São José dos Campos, SP.E-mail:mirabel@iae.cta.br 


\section{Introdução}

Uma das maiores dificuldades para se alcançar a máxima economia de peso na fabricação de componentes estruturais de aeronaves, usando compósitos avançados, é a tendência que esses materiais têm à formação de vazios e trincas no interior e na superfície dos componentes.

A formação de vazios em compósitos avançados deve-se, em geral, a bolhas de ar aprisionadas no sistema de resina quando da sua formulação, bolsas de resina, umidade absorvida pelo pré-impregnado durante a sua armazenagem e seu processamento e ciclos de cura inadequados, tais como valores de pressão e temperaturas não adequados ${ }^{[1,2]}$.

A formação e o crescimento de vazios causam a perda da resistência, rigidez e vida em fadiga do laminado, muitas vezes resultando em falha catastrófica. Sabe-se que, a resistência dos compósitos a alguns tipos de esforços (cisalhamento interlaminar e compressão, entre outros) diminui com o aumento do volume de vazios ${ }^{[2-4]}$. Além disso, quando expostos aos efeitos ambientais, como umidade do ar, altas temperaturas e radiação ultravioleta, os compósitos podem ter suas propriedades físicas e mecânicas afetadas. Um fato significativo é que os vazios favorecem a absorção de água pela matriz polimérica, implicando em um aumento potencial dos vazios préexistentes ${ }^{[3,5,6]}$.

Por isto, é muito importante o controle da presença de vazios em estruturas aeroespaciais. Para detectar e caracterizar essas descontinuidades, a indústria aeronáutica faz uso de técnicas de inspeção não-destrutivas. Dentre essas, o ensaio ultra-sônico, em técnicas de pulso-eco ou transmissão total por coluna d'água, é o mais utilizado. Por meio desse ensaio pode-se caracterizar: a qualidade da cura, áreas ricas ou pobres em resina, desalinhamento de fibras, delaminação, porosidade, trincas interlaminares, inclusões, danos por ferramentas, danos por impacto e degradação ambiental ${ }^{[5,6]}$.

Portanto, na indústria aeronáutica o conhecimento e estabelecimento da influência da porosidade na resistência de compósitos poliméricos são parâmetros de grande importância na qualificação das peças aeronáuticas. Assim, este artigo descreve o estudo do efeito da porosidade na resistência ao cisalhamento interlaminar do sistema de compósitos de tecido e fita de carbono aglutinadas em matriz epóxi, afim de colaborar diretamente com a indústria aeronáutica na determinação do efeito de defeitos em compósitos avançados . Os laminados foram produzidos de forma semelhante, bem como, o processo de introdução de vazios (até $12 \%$ de porosidade), possuindo os laminados de tecido de carbono/epóxi uma espessura final nominal de $4 \mathrm{~mm}$ e os de fita unidirecional/epóxi $3 \mathrm{~mm}$. Tais compósitos foram avaliados por inspeção ultra-sônica e os valores de atenuação medidos foram convertidos em coeficientes de absorção para permitir uma normalização dos dados. Em seguida, ensaios de resistência ao cisalhamento interlaminar (ILSS) foram conduzidos para avaliar a influência de vazios na resistência mecânica dos materiais estudados. Além disso, uma inspeção microscópica foi realizada para observar a distribuição e a forma dos vazios. Os ensaios de resistência ao cisalhamento interlaminar e microscopia eletrônica de varredura tiveram como objetivo comparar o efeito da porosidade em compósitos de tecidos e fita unidirecional.

\section{Experimental}

\section{Descrição das amostras}

Dois tipos de compósitos foram estudados neste trabalho: laminados de tecido de carbono e laminados de tape de carbono ambos impregnados com matriz epóxi. Para cada tipo de compósito foram produzidas diferentes quantidades de vazios. Laminados com alto nível de porosidade foram obtidos combinandose a técnica de controle da pressão efetiva exercida sobre a resina líquida durante a cura, utilizada por Almeida e Nogueira Neto (1994) ${ }^{[5]}$, com a técnica de introdução de umidade entre as camadas durante a laminação, como sugerido por Gürdal e colaboradores (1991). A umidade foi introduzida aspergindo-se água uniformemente sobre as camadas do laminado produzindo uma porosidade homogênea. Todos os corpos-de-prova (cdps) foram curados em autoclave a $180^{\circ} \mathrm{C}$.

Foram produzidas 7 placas de laminados, incluindo uma considerada como referência, com baixo nível de vazios, sendo denominadas de EP-1, EP-2, EP-3, EP-4, EP-5, EP-6 e EP-7. Tais placas foram fabricadas utilizando-se 14 camadas de pré-impregnado de tecido de carbono com matriz epóxi (F584) fornecida pela empresa Hexcel Composite e 
empilhadas a $\left(0,90^{\circ}\right)$, contendo de $0-6 \%$ de vazios de acordo com os ensaios de digestão ácida ASTM D3171- Standard Test Method for Content of ResinMatrix Composites by Matrix Digestion . Estas amostras continham entre $64-72 \%$ de fração volumétrica em fibras de carbono e possuíam $4 \mathrm{~mm}$ de espessura.

O segundo tipo de laminado, foi produzido com pré-impregnado de tape de carbono com epóxi e foi preparado da mesma forma citada anteriormente, sendo denominados de: TAP-1, TAP-2, TAP-3, TAP-4, TAP-5 e TAP-6, contendo de 0 - 12\% em fração de vazios nas amostras e entre $64-70 \%$ de fração volumétrica em fibras de carbono, com $3 \mathrm{~mm}$ de espessura final.

\section{Análise Microestrutural}

As análises microscópicas foram realizadas observando-se as superfícies dos corpos-de-prova preparados para o ensaio de cisalhamento interlaminar, antes e após o ensaio, utilizando-se um equipamento da Zeiss, modelo Digital Scanning Microscope-950, sem a necessidade de metalização das superfícies, devido à característica condutora da fibra de carbono e dos recursos do equipamento utilizado.

\section{Qualificação dos cdps}

Todos os laminados fabricados foram inspecionados por um detetor ultra-sônico de falhas Reflectoscope S80, provido de emissor Automation X19265 de diâmetro 0,750 polegadas e frequiência de $5 \mathrm{MHz}$. A fim de diminuir as perdas espúrias para o meio circundante, um jato de água foi utilizado para transportar o feixe de ultra-som entre o emissor e a placa e entre a placa e o receptor. Outros cuidados, como alinhamento do emissor e do receptor e incidência perpendicular, foram tomados para diminuir as perdas.

Para a inspeção, a placa foi montada a igual distância do emissor e do receptor, os quais foram transportados por uma ponte Automation US 640.

O sistema de medição por ultra-som é calibrado de modo que o sinal sem atenuação tenha amplitude de $10 \mathrm{~V}$. O processo de calibração é feito utilizandose um laminado padrão de carbono/epóxi, para compensar a atenuação, devido às superfícies do laminado. Desta forma, a atenuação medida do sinal corresponde somente às perdas no material.

A atenuação total medida pelo ultra-som para cada espécime é dada pela equação 1 a seguir ${ }^{[5]}$ :

$$
-20 \log \left(\frac{V_{1}}{V_{2}}\right)=A_{f}+A_{b}+A_{t}=A_{T}
$$

onde:

$V_{2}$ é o sinal emitido em volts (V);

$V_{l}$ é o sinal recebido em volts $(\mathrm{V})$;

$A_{f}$ é a atenuação na superfície frontal da amostra $(\mathrm{dB})$; $A_{b}$ é a atenuação na superfície posterior da amostra $(\mathrm{dB})$;

$A_{t}$ é a atenuação por transmissão através da espessura da amostra $(\mathrm{dB}) \mathrm{e}$

$A_{T}$ é a atenuação total do espécime $(\mathrm{dB})$.

De acordo com Stone e Clark ${ }^{[6]}, \mathrm{A}_{\mathrm{f}}$ e $\mathrm{A}_{\mathrm{b}}$ são independentes em condições planas e seria de se esperar constantes para placas de diferentes espessuras. Entretanto, $\mathrm{A}_{\mathrm{t}}$ aumenta linearmente com a espessura $t$ da placa. Assim, pode-se definir o coeficiente de absorção, $\alpha$ como: (equação 2)

$$
A_{t}=\alpha t
$$

onde $\alpha$ é a medida em $\mathrm{dB} / \mathrm{mm}$ e depende da condição interna do compósito e principalmente do conteúdo de vazios.

\section{Ensaio Mecânico}

Neste estudo foi adotado o método de ensaio de cisalhamento interlaminar de 3 pontos "short beam" (ILSS) que é rápido, simples e adequado para controle da qualidade.

O ensaio em três pontos descrito na norma ASTM D2344 ${ }^{[7]}$ estabelece para os compósitos reforçados com fibras de carbono corpos-de-prova de razão vão/ espessura igual a 4 e razão comprimento/espessura igual a 6. Foram utilizados 10 corpos-de-prova para cada lote de compósito obtido com vazios e para o lote de referência livre de vazios, com dimensões de $24 \mathrm{~mm}$ x 6,35 mm x 4,1 mm (comprimento x largura $\mathrm{x}$ espessura) para tecido de carbono/epóxi e $24 \mathrm{~mm} \mathrm{x}$ 6,35 $\mathrm{mm}$ x 3,0 $\mathrm{mm}$ para tape de carbono/epóxi.

Os ensaios foram realizados em uma máquina universal de ensaios INSTRON, com célula de carga de 5 toneladas, acoplada a um computador que processa graficamente as curvas de carga versus deslocamento.

\section{Resultados e Discussão}

\section{Análise Microestrutural}

A microscopia eletrônica de varredura (MEV) foi

Polímeros: Ciência e Tecnologia, vol. 11, no 4, p. 182-189, 2001 
utilizada para obter dados sobre a distribuição, formato e localização preferencial dos vazios nas amostras tanto de tecido, como de tape de carbono/epóxi. A fotomicrografia da Figura 1 mostra uma vista geral de laminados de tecido e tape de carbono/epóxi sem porosidade. A análise desta micrografia mostra uma distribuição homogênea da matriz nas fibras, ausência de vazios ou trincas. As regiões mais claras devem-se a pequenas bolsas de resina. Já na fotomicrografia 2(a) pode-se observar a ocorrência de vazios, distribuídos de forma heterogênea na amostra, localizando-se preferencialmente na interface tra$\mathrm{ma} /$ urdume ou na interface fibra/matriz. A Figura 2(b) mostra a fotomicrografia de laminados de tape de carbono/epóxi com porosidade, sendo poros pequenos (menores que os de tecido epóxi), de formato esférico e provavelmente propagadores de defeitos principalmente quando localizados na interface fibra/ matriz.

Observou-se, também, na Figura 3 que nos cdps de tecido de carbono/epóxi ensaiados as trincas se

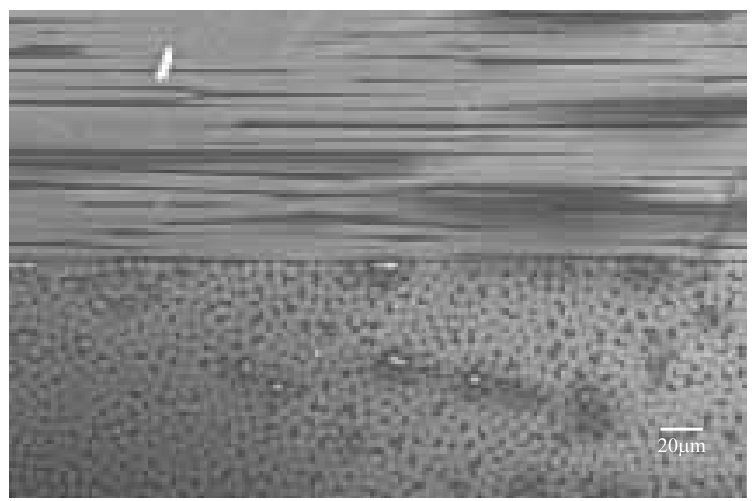

(a)

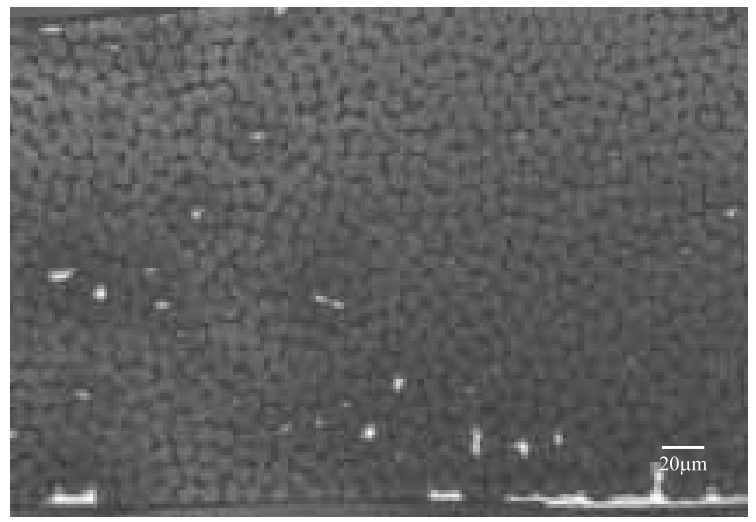

(b)

Figura.1. Fotomicrografias das amostras de tecido (a) e tape de carbono epóxi (b) isentos de vazios, com magnificação de 800 e 1000X, respectivamente.

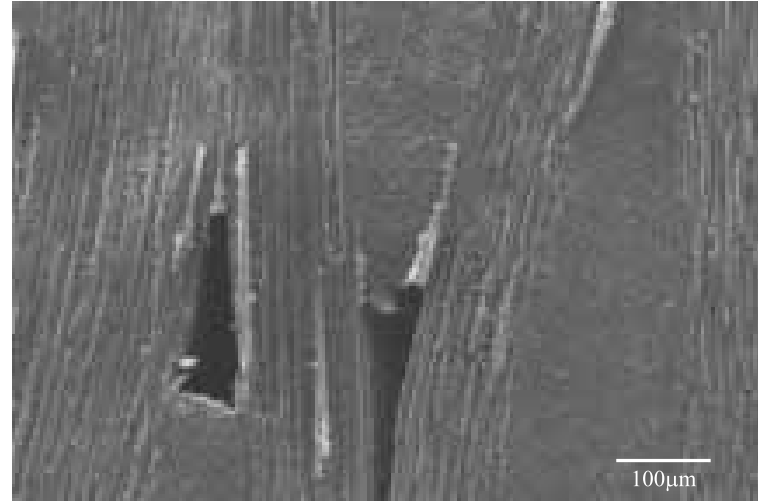

(a)

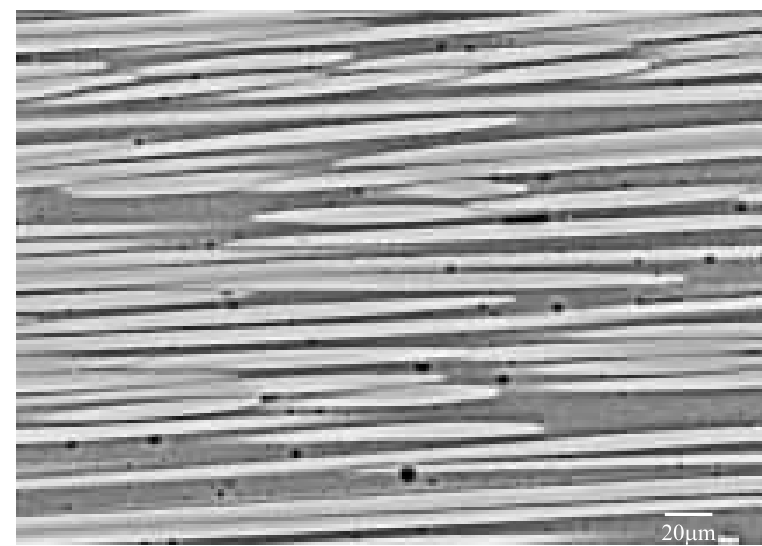

(b)

Figura 2. Fotomicrografias das amostras de (a) tecido e (b) tape de carbono epóxi contendo porosidade, 1000X.

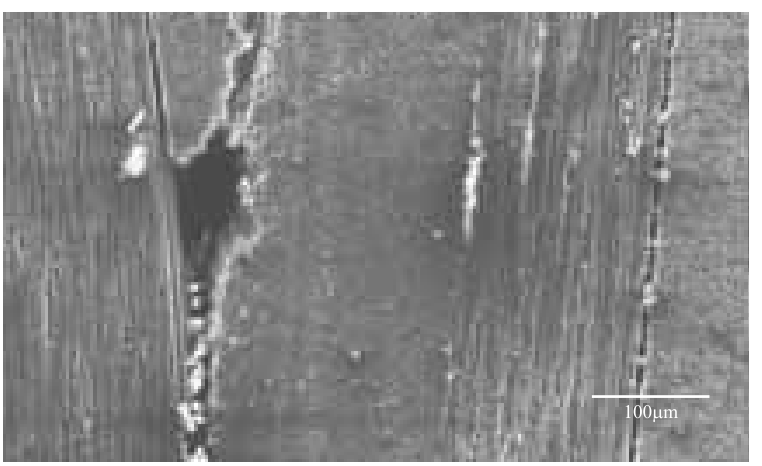

Figura 3. Fotomicrografia da amostra de tecido de carbono/epóxi já ensaiada, 1200X.

propagam a partir de poros com formato triangular, confirmando que os vazios são propagadores de trincas e defeitos. Isto pode ser afirmado uma vez que nos cdps não ensaiados não se verifica trincas, portanto tais fraturas não são provenientes de defeitos de fabricação, ou seja, estas surgem somente após o ensaio de cisalhamento.

Assim, pode-se, inicialmente, concluir que esses vazios tendem a ser formados ao longo da interface 
trama/urdume e da fibra/matriz. Entretanto, o seu formato e tamanho tendem a ser ligeiramente diferentes nesses dois casos. Nas amostras de tape de carbono epóxi observam-se vazios de formato esférico, menores que os do tecido epóxi, que muitas vezes tendem a coalescer formando uma região com um defeito maior, favorecendo ainda mais a propagação de trincas. Já as amostras de tecido de carbono/epóxi, os vazios são triangulares, como resultado da possível coalescência de pequenos vazios esféricos nas regiões próximas ao cruzamento de trama com o urdume $^{[8]}$

\section{Atenuação do ultra-som}

A Tabela 1 mostra os resultados obtidos de coeficiente de absorção para cada conjunto de laminados. Nos dois casos o laminado referência possui o menor coeficiente de absorção $(0,11$ $\mathrm{dB} / \mathrm{mm}$ ), uma vez que o sinal emitido é quase igual ao valor do sinal recebido já que há baixa perda de sinal no caminho percorrido pelo ultra-som, pois o conteúdo de vazios é baixo.

Verifica-se na Tabela 1, que a quantidade de vazios encontrada para cada grupo relaciona-se diretamente com o valor de atenuação medido pelo ultra-som. Ou seja, os resultados da digestão ácida $\left(\mathrm{V}_{\mathrm{v}}\right)$ confirmam os dados obtidos pelo ultra-som.

A Figura 4 apresenta a quantidade de vazios de cada grupo de laminado em função do coeficiente de absorção, $\alpha$.

Observa-se na Figura 4, uma relação bi-linear, para os laminados de tecido de carbono/epóxi, e uma relação linear, para os laminados de tape de carbono/

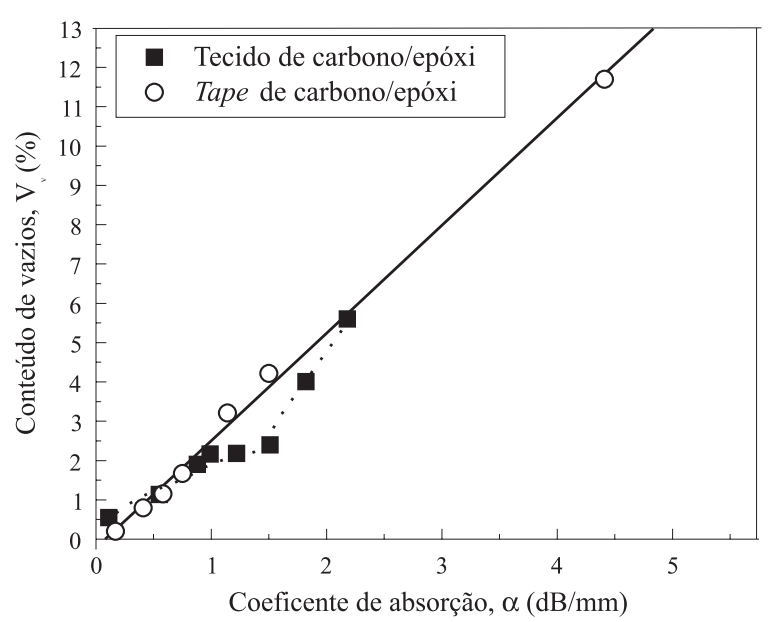

Figura 4. Coeficiente de absorção em função do conteúdo de vazios para tecido e tape de carbono/epóxi.

epóxi, entre a quantidade de vazios e o coeficiente de absorção obtido pelo ultra-som. Esse tipo de relação foi notada, também, por Stone e Clark ${ }^{[6]}$, bem como por Almeida e Nogueira Neto ${ }^{[5]}$. Stone e Clark ${ }^{[6]}$ afirmam que essa reta pode ser dividida em duas equações lineares (como mostra o gráfico de tecido de carbono/epóxi), sendo cada uma delas função do tamanho e da forma dos vazios. Para $V_{v}$ aproximadamente menor que $1,5 \%$, os vazios tendem a ser esféricos, e em geral, são formados devido à saída de diferentes tipos de voláteis existentes nos pré-impregnados, que quando evaporam geram bolhas na matriz, principalmente se a pressão utilizada na compactação do laminado for baixa. Essa, então, seria a primeira relação linear, ou seja, entre vazios pequenos e esféricos. A segunda relação linear existente é aquela onde o conteúdo de vazios é maior que $1,5 \%$. Neste caso, os vazios tornam-se achatados,

Tabela 1. Valores médios de coeficiente de absorção $\alpha$ digestão ácida $(\mathrm{V})$ e conteúdo de vazios $\left(\mathrm{V}_{\mathrm{v}}\right)$ para tecido de carbono/epóxi e tape de carbono/epóxi.

\begin{tabular}{|c|c|c|c|c|c|}
\hline $\begin{array}{l}\text { Laminado de } \\
\text { tecido de } \\
\text { carbono/epóxi }\end{array}$ & $\begin{array}{c}\text { Coeficiente de } \\
\text { absorção } \\
\alpha(\mathrm{dB} / \mathrm{mm})\end{array}$ & $\begin{array}{c}\text { Quantidade de } \\
\text { vazios, } \\
\mathbf{V}_{\mathrm{v}}(\%) \\
\end{array}$ & $\begin{array}{l}\text { Laminado de } \\
\text { tape de } \\
\text { carbono/epóxi }\end{array}$ & $\begin{array}{c}\text { Coeficiente de } \\
\text { absorção } \\
\alpha(\mathrm{dB} / \mathbf{m m})\end{array}$ & $\begin{array}{c}\text { Quantidade de } \\
\text { vazios, } \\
\mathrm{V}_{\mathrm{v}}(\%) \\
\end{array}$ \\
\hline Referência & 0,11 & 0,6 & Referência & 0,17 & 0,2 \\
\hline EP-1 & 0,55 & 1,4 & TAP-1 & 0,41 & 0,8 \\
\hline EP-2 & 0,88 & 1,9 & TAP-2 & 0,58 & 1,2 \\
\hline EP-3 & 0,99 & 2,2 & TAP-3 & 0,75 & 1,7 \\
\hline EP-4 & 1,22 & 2,2 & TAP-4 & 1,14 & 3,2 \\
\hline EP-5 & 1,51 & 2,4 & TAP-5 & 1,50 & 4,2 \\
\hline EP-6 & 1,82 & 4,0 & TAP-6 & 4,41 & 11,7 \\
\hline EP-7 & 2,18 & 5,6 & & & \\
\hline
\end{tabular}


alongados com forma triangular e aparecem na direção longitudinal das fibras e em maior quantidade que as descontinuidades esféricas. Esses quase sempre são causados por umidade ou bolsas de ar aprisionadas na matriz.

Com isso, esses dois tipos de vazios sugerem uma relação bi-linear como alternativa para descrever a variação entre o conteúdo de vazios e o coeficiente de absorção $\alpha^{[6] \text {. }}$

Porém, para o caso de laminados de tape de carbono/epóxi observa-se apenas uma relação linear, que pode ser explicada com base nas fotomicrografias (Figura 2(b)), onde verifica-se somente um tipo de defeito circular distribuído de maneira mais homogênea no compósito.

\section{Resistência ao Cisalhamento Interlaminar}

Os resultados do ensaio de cisalhamento interlaminar obtidos para cada grupo de laminados encontram-se na Tabela 2.

Correlacionando-se os dados das Tabelas 1 e 2 tem-se que, tanto nos compósitos de tecido como nos de tape, o laminado com maior resistência ao cisalhamento interlaminar é a referência, uma vez que este é o que possui menor quantidade de vazios.

Esse resultado está de acordo com o obtido para os valores de coeficiente de absorção $\alpha$ e da quantidade de vazios existente em cada grupo. Assim, quanto maior a quantidade de vazios em uma placa menor a sua resistência ao cisalhamento interlaminar. Este comportamento era esperado, pois como se sabe, a existência de defeitos em compósitos piora suas propriedades mecânicas $^{[3,5,6]}$.

De posse dos valores das Tabelas 1 e 2 construiuse gráficos de resistência ao cisalhamento interlaminar em função do conteúdo de vazios, confirmando que o ILSS diminui com o aumento do conteúdo de vazios no laminado. Essa redução nos valores de ILSS obedece, ainda, um decaimento exponencial como mencionado na literatura ${ }^{[8-11]}$.

Apesar de todas as referências ${ }^{[8-11]}$ concordarem que existe um decréscimo das propriedades mecânicas com o aumento do conteúdo de vazios, não existe um consenso quanto à magnitude desse efeito. Esse fato pode ser explicado, entre outros motivos, com base no conhecimento de que a influência do conteúdo de vazios nas propriedades mecânicas de um compósito depende do tipo de pré-impregnado utilizado na produção do laminado, do processamento e da técnica utilizada na avaliação do compósito (por exemplo, diferentes freqüências utilizadas no ultrasom geram valores de atenuação diferentes). Assim, somente resultados de compósitos produzidos e ensaiados de maneira semelhante é que fornecem resultados comparáveis.

Além disso, outro fator importante a ser lembrado é que a distribuição, a localização, o formato e o tamanho dos vazios nos laminados produzem efeitos diferentes nas propriedades mecânicas dos compósitos com descontinuidades. Porém, na tentativa de se comparar resultados, são propostos na literatura critérios de falha para laminados com concentrações de tensões ${ }^{[11-15]}$. Neste trabalho foi utilizado o critério de Mar e $\operatorname{Lin}^{[12]}$ que afirma que a trinca em um compósito inicia-se na interface fibra/matriz. Esses autores mostraram que a resistência de um laminado está diretamente relacionada com a extremidade da trinca, que por sua vez, encontra-se na interface de dois materiais diferentes ${ }^{[12]}$.

O critério de Mar-Lin pode ser modificado para a análise de compósitos contendo vazios assumindose que:

$$
\sigma_{\mathrm{f}}=\mathrm{H}(\alpha)^{-\mathrm{m}}
$$

Onde: $\sigma_{f}$ é a tensão de fratura, $H$ é a tenacidade do laminado, $\alpha$ é o coeficiente de absorção em $\mathrm{dB} / \mathrm{mm}$, e $-m$ é a ordem de singularidade da tensão.

O critério proposto pela equação (3) implica que abaixo do valor crítico, correspondente ao coeficiente de absorção $\alpha_{c r}$, o conteúdo de vazios não afeta a resistência do laminado. A característica desse critério é suportada por resultados físicos e dados experimentais $^{[16]}$

Tabela 2. Medidas de resistência ao cisalhamento interlaminar dos laminados de tecido e de tape de carbono/epóxi.

\begin{tabular}{cccc}
\hline $\begin{array}{c}\text { Laminado de tecido } \\
\text { de carbono/epóxi }\end{array}$ & $\begin{array}{c}\text { ILSS } \\
(\mathbf{M P a})\end{array}$ & $\begin{array}{c}\text { Laminado de tape } \\
\text { de carbono/epóxi }\end{array}$ & $\begin{array}{c}\text { ILSS } \\
\text { (MPa) }\end{array}$ \\
\hline Referência & $82,2 \pm 3$ & Referência & $102,2 \pm 2$ \\
EP-1 & $71,4 \pm 3$ & TAP-1 & $92,6 \pm 6$ \\
EP-2 & $67,8 \pm 2$ & TAP-2 & $78,8 \pm 4$ \\
EP-3 & $65,7 \pm 9$ & TAP-3 & $76,4 \pm 3$ \\
EP-4 & $65,3 \pm 4$ & TAP-4 & $63,3 \pm 3$ \\
EP-5 & $63,5 \pm 4$ & TAP-5 & $62,1 \pm 4$ \\
EP-6 & $59,5 \pm 3$ & TAP-6 & $53,0 \pm 7$ \\
EP-7 & $54,5 \pm 3$ & & \\
\hline
\end{tabular}




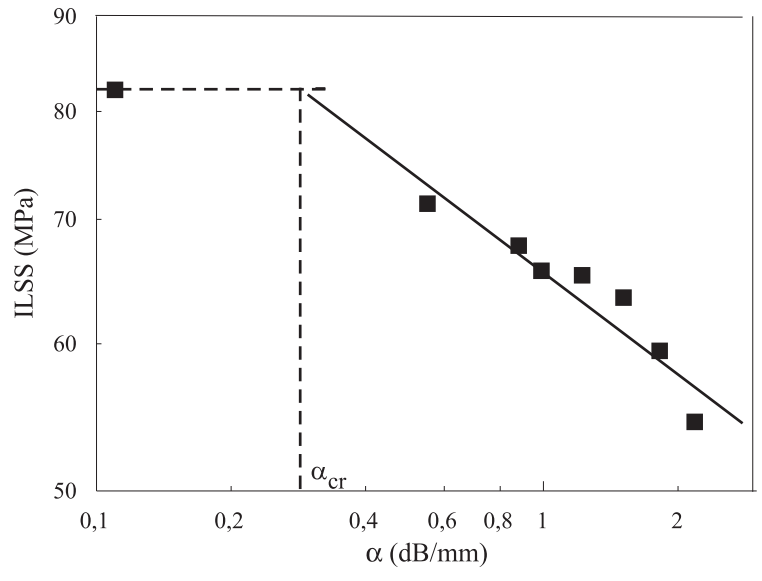

Figure 5. Logaritmo da resistência ao cisalhamento interlaminar em função do logaritmo do coeficiente de absorção, $\alpha$ para o laminado de tecido de carbono/epóxi.

Assim, o critério de Mar-Lin foi aplicado aos dados das Tabelas 1 e 2, obtendo-se novos gráficos de logaritmo de ILSS em função do logaritmo de $\alpha$ para os laminados de tecido de carbono/epóxi e tapel epóxi (Figuras 5 e 6 ).

As figuras 5 e 6 mostram um bom ajuste linear para os pontos experimentais obtidos, sendo que os valores de $m$ e de $H$ são bastante próximos para os dois tipos de sistemas, onde $m=0,174, H=65,80$ $\operatorname{MPa}(\mathrm{dB} / \mathrm{mm})^{0,174}$ e $\alpha_{c r}=0,277 \mathrm{~dB} / \mathrm{mm}$, para laminados de tecido de carbono/epóxi e $m=0,22, H=$ $69,18 \mathrm{MPa}(\mathrm{dB} / \mathrm{mm})^{0,22}$ e $\alpha_{c r}=0,21 \mathrm{~dB} / \mathrm{mm}$ para tape de carbono/epóxi. Esse valor de $a_{c r}$ corresponde a um conteúdo de vazios de aproximadamente $0,9 \%$ no caso de laminados de tecido de carbono/epóxi e de $0,75 \%$ para laminados de tape de carbono/epóxi. Ou seja, laminados de carbono/epóxi com porosidade maior que $0,9 \%$ e laminados de tape de carbono/epóxi com

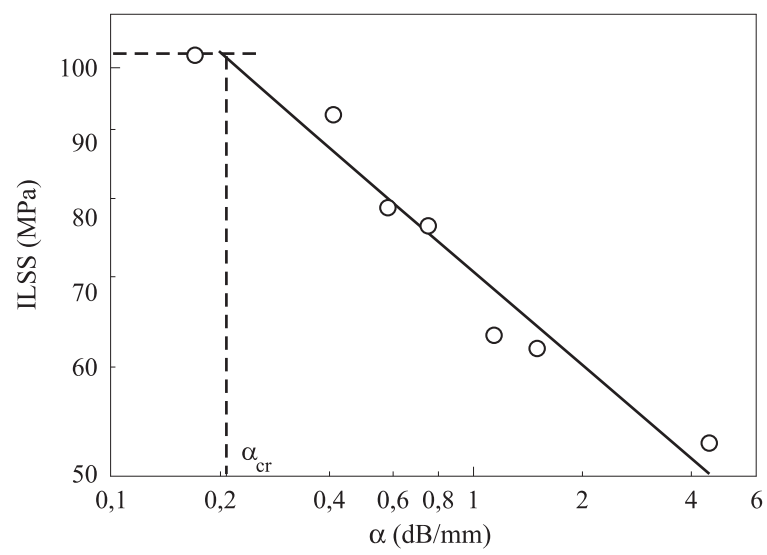

Figura 6. Logaritmo da resistência ao cisalhamento interlaminar em função do logaritmo do coeficiente de absorção, $\alpha$ para o laminado de tape de carbono epóxi porosidade maior que $0,75 \%$ terão seus valores de resistência ao cisalhamento interlaminar diminuídos.

A literatura ${ }^{[3,12,17]}$ mostra que utilizando-se o critério de Mar-Lin, os valores encontrados para $m$ experimental estão no intervalo de $0,18-0,35$. Portanto, os valores de $m$ encontrados no presente trabalho ( $m=0,174$ e $m=0,22)$, estão dentro da faixa esperada. Esta faixa possui tal variação devido às diferenças existentes entre o tipo de matriz utilizada em cada trabalho, ao número de camadas empilhadas na produção do laminado, aos diferentes valores de fração volumétrica em fibras e ao tipo de carregamento a que foi submetida a amostra.

\section{Conclusões}

As fotomicrografias mostram que a porosidade de compósitos produzidos com tecido de carbono/ epóxi possuem formato triangulares. Já os laminados de tape epóxi possuem poros esféricos, menores que os de tecido carbono/epóxi. Porém, ambos tendem a se alojar na interface fibra/matriz. Os laminados de tecido de carbono/epóxi apresentam uma relação bilinear entre a quantidade de vazios e o coeficiente de absorção $\alpha$. Enquanto que, os laminados de tape de carbono/epóxi apresentam uma relação linear.

O ensaio de cisalhamento interlaminar realizado nos laminados com diferentes níveis de porosidade confirmou o fato de que quanto maior a quantidade de vazios existente em um compósito menor a sua resistência mecânica. O critério de fratura de Mar-Lin utilizado no presente trabalho, apresentou bom ajuste mostrando-se adequado para o estudo de porosidade em compósitos. Além disso, os resultados de $m(m=0,174 e$ 0,22) encontrados concordam com a faixa relatada na literatura. Por meio desse critério observou-se que somente laminados com porosidade acima de $0,9 \%$ para tecido de carbono/epóxi e acima de $0,75 \%$ para laminados de tape de carbono/epóxi é que têm a sua resistência mecânica reduzida, sendo que este último tem menor tolerância a danos que o tecido de carbono.

\section{Agradecimentos}

Os autores agradecem à FAPESP pelo suporte financeiro 98/10079-1, à empresa Hexcel Composites por ter cedido os pré-impregnados utilizados no presente trabalho, bem como, à EMBRAER por permitir a utilização de suas instalações na preparação dos laminados. 


\section{Referências Bibliográficas}

1. Wiedemann, G. e Rothe, H. "Processing and Fabrication”. Elsevier Applied Science, London, v..5, p.83119 (1986).

2. Costa, M.L., Rezende, M.C. e Almeida, S.F.M. - Influence of Porosity on the Interlaminar Shear Strength of Carbon/Epoxy and Carbon/Bismaleimide Fabric Laminates, Composite Science and Technology, 61, p. 2101-2108 (2001).

3. Jeong, H. - J. Comp. Mat., 31(3), p.276-292 (1997).

4. Savage, G. "Carbon-carbon composites". Chapman \& Hall, London, (1993).

5. Almeida, S.F.M. e Nogueira Neto, Z.S. - Comp. Struct., 28, p.139-148 (1994).

6. Stone, D.E. e Clark, B. - Non Destructive Testing, July, p.137-145 (1975).

7. ASTM D2344. Standard test method for apparent interlaminar shear strength of parallel fiber composites by short-beam method. Philadelphia, PA.: American Society for Testing and Materials, (1984).

8. Bowles, K. J. e Frimpong, S. - J. Comp. Mat., 26, 10, p.1487-1509 (1992).

9. Suarez, J.C., Molleda F. And Güemes A. Void Content in Carbon Fiber/Epoxy Resin Composites and its Ef- fects on Compressive Properties. In: Proceedings of Ninth International Conference on Composite Materials, Editor: A Miravete, Woodhead Publishing Limited, Madrid, Spain, ICCM-9, July, v. VI, p.589596 (1993).

10. Gürdal, Z., Tomasino, Ap. and Biggers, S.B. - Sampe J., 27, 4, p.3949 (1991).

11. Olivier, P. Cottu, J.P. E Ferret, B. - Composites, 26, 7, p.509-515 (1995).

12. Mar, J. W. and Lin, K, Y. Journal Aircraft, 14, p.703704 (1977).

13. Whitney, J. M. E Nuismer, R. J- J. Comp. Mater, 5, p.253-265 (1974).

14. Waddoups, M.E., Eisenmann, J.R. and Kaminski, B.E. - J. Comp. Mater., 5, p.446-454 (1971).

15. Soriano, E.A Estudo sobre a Sensibilidade ao Entalhe de Laminados de Carbono/Epóxi. Tese de Mestrado, Instituto Tecnológico de Aeronáutica, Brasil, (1990).

16. Tang, J. M., Lee, I. W. E Springer, G.S - J. Comp. Mater. 21, p.421-440 (1987).

17. Soriano, E.A and Almeida, S.F.M. - Comp. Sci. Tech., 59, p.1143-1151 (1999).

Recebido: 11/06/01

Aprovado: 15/11/01 